Pregledni rad https://doi.org/10.31784/zvr.7.1.18 Datum primitka rada: 15. 1. 2019. Datum prihvaćanja rada: 26. 2. 2019.

\title{
PROTOKOLI TEHNIČKE ANALIZE U RAZLUČIVANJU PODCIJENJENOSTI OD NISKE CIJENE
}

\author{
Vedran Šarlija \\ Struč. spec. pod., Tibljaška cesta 2, 51000 Rijeka, Hrvatska; e-mail: vedranv995@gmail.com
}

Marijana Vuraić-Kudeljan

Mr. sc., zamjenica ravnatelja, Ministarstvo financija, Porezna uprava, Boškovićeva 5, 10000 Zagreb,

Hrvatska; e-mail: marijana.vuraic-kudeljan@porezna-uprava.hr

\section{Denis Buterin}

Mr. sc., v. pred., Veleučilište u Rijeci, Vukovarska 58, 51000 Rijeka, Hrvatska; e-mail: dbuterin@veleri.hr

\section{SAŽETAK}

Financijska tržišta bitna su sastavnica gospodarskog okruženja, a njihova kretanja često su izučavale različite interesne skupine. Premda nije moguće s potpunom sigurnošću predvidjeti kretanja na financijskim tržištima, zahvaljujući razvoju znanosti i tehnologije danas postoje analitički protokoli $i$ alati kojima se ta kretanja ipak mogu kvantificirati, uvažavajući pritom određena ograničenja te određenu razinu rizika. Autori u radu istražuju kretanje cijene dionice grupacije Đuro Đaković d. d. te upotrebom pouzdanih pokazatelja tehničke analize izvode zaključke o budućim kretanjima trendova i buducim cjenovnim razinama u kratkom, dugom i srednjem roku, s ciljem primjene rezultata na donošenje odluka u investicijskim procesima. U svakom od promatranih razdoblja autori uočavaju prisutnost negativnog trenda. Ovakvi su rezultati začuđujući, uzme li se u obzir relativno povoljan položaj poduzeća na tržištu te njegova relativna gospodarska snaga. Ipak, analiza momentuma, indeksa relativne snage i MACD signala ukazuje na naznake slabljenja negativnog trenda u kratkom i srednjem razdoblju, dok se oporavak i porast na eventualne više cjenovne razine mogu očekivati tek u dužem roku.

Ključne riječi: tehnička analiza, financijska tržišta, dionica, rizik, indikatori

\section{UVOD}

Financijska tržišta kao zanimljiv čimbenik okruženja česta su tema izučavanja u brojnim znanstvenim i stručnim radovima. Osim promatranja tržišta u kraćim vremenskim periodima, od velikog su značaja kontinuirana promatranja tržišta u dužim vremenskim razdobljima. Promatrajući 
financijska tržišta moguće je anticipirati buduća događanja, ali zbog prevelikog broja faktora nije moguće bez izuzetaka is potpunom sigurnošću utvrditi smjer i intenzitet njihovog kretanja.

U ovom radu analiziraju se odabrani pokazatelji radi proučavanja i predviđanja sadašnjih i budućih tijekova cijene dionice Đuro Đaković d. d. Promatrano poduzeće ima dugu povijest djelovanja, veliku važnost u hrvatskoj industriji te prepoznatljivost stečenu i izvan granica Hrvatske. Ova prepoznatljivost rezultat je višegodišnjih suradnji s poznatim svjetskim industrijskim kompanijama. Osim toga, dionica Đuro Đaković d. d. kotira na Zagrebačkoj burzi i u uvjetima plitkog tržišsta može se smatrati jednom od njenih postojanijih vrijednosnica. U vrijeme kraha investicijskog balona i značajnih korekcija cijena, promatrana dionica izgubila je velik dio svoje vrijednosti, što se može pripisati učinku prelijevanja u vrijeme krize (Živkov et al., 2018). Pristupanje Hrvatske Sjevernoatlantskom savezu, kao i pridruživanje Europskoj uniji i posljedično otvaranje vojnog i ostalih tržišta, nije polučilo učinke u smislu porasta cijene promatranog poduzeća. Dapače, stječe se dojam da je ta dionica duže vrijeme podcijenjena, pa se postavlja pitanje pružaju li se u tom smislu eventualne mogućnosti za ostvarivanje ulagačkog profita. Autori pomoću protokola tehničke analize traže odgovor na pitanje može li se i kada očekivati promjena trenda, odnosno, upotrebljavaju navedene protokole u svrhu razlučivanja privremene podcijenjenosti od niske cijene trajnijeg karaktera.

Tehničkom se analizom proučava, prati, promatra i pretpostavlja buduće kretanje, smjer i snaga prošlih i budućih cjenovnih promjena, ne istražujući pritom uzroke i razloge pojedinih kretanja. Tehnička analiza dionice Đuro Đaković d. d. napravljena je proučavanjem trendova i pomičnih prosjeka te korištenjem oscilatora. Pokazatelji korišteni u ovom radu smatraju se vrlo pouzdanima te se u praksi i u znanstvenim istraživanjima često koriste. Rezultati istraživanja ukazuju na slabljenje negativnog trenda i očekivanu promjenu trenda u dugom roku, a sistematizirani su u zaključku rada.

\section{GRUPACIJA ĐURO ĐAKOVIĆ D. D.}

Grupacija Đuro Đaković d. d. kao matica ima četiri društva u kojima ima prevladavajući utjecaj s više od 50 \% glasova na glavnoj skupštini. Pored toga ima manjinski udio u još dva društva. Društva unutar grupacije su samostalna, a matica ih nadzire sukladno Zakonu o trgovačkim društvima. Đuro Đaković jedna je od najvećih industrijskih grupacija u Hrvatskoj s dugom tradicijom i ugledom na globalnom tržištu. Opsežan popis referenci grupacije uključuje velik raspon realiziranih projekata različitog opsega i složenosti, kao što su projektiranje i izgradnja širokog spektra procesnih posuda pod tlakom za naftnu i petrokemijsku industriju, spremnika za naftu i plin, proizvodnja tenkova, borbenih oklopnih vozila, strojeva za razminiranje, teretnih vagona svih vrsta, uključivo i cisterne za prijevoz tekućina i plinova, izgradnja čeličnih konstrukcija za mostove, izgradnja tvornica po sistemu ključ u ruke, oprema za termoelektrane i hidroelektrane, te obnovljive izvore energije i sl. Đuro Đaković d. d. glavni je hrvatski dobavljač tenkova i borbenih vozila, NATO interoperabilnih teretnih vagona za različite vrste roba, kao i pružatelj pune podrške tijekom životnog ciklusa i svih razina održavanja za proizvode iz svog portfelja (Đuro Đaković, 2017). 
Radi boljeg razumijevanja značaja grupacije Đuro Đaković $d$. d. objašnjeni su izabrani najbitniji podaci o samom poduzeću. U tablici 1 prikazan je broj zaposlenih u promatranoj grupaciji, a u grafikonu 1 kretanje broja zaposlenih u posljednje četiri godine.

Tablica 1. Broj zaposlenih po poduzećima grupacije na dan 31. 3. 2017. / 31. 3.2018.

\begin{tabular}{lcc} 
Društvo & $\begin{array}{c}\text { Broj zaposlenih } \\
\text { Q1 2017. }\end{array}$ & $\begin{array}{c}\text { Broj zaposlenih } \\
\text { Q1 2018. }\end{array}$ \\
\hline$\boxminus \boxminus$ Specijalna vozila d.d. & 501 & 551 \\
\hline$\boxminus \boxminus$ Industrijska rješenja d.d. & 295 & 234 \\
\hline$\boxminus \boxminus$ Strojna obrada d.o.o. & 157 & 166 \\
\hline$\boxminus \boxminus$ Energetika i infrastruktura d.o.o. & 25 & 24 \\
\hline E Grupa d.d. & 29 & 24 \\
\hline Ukupno & $\mathbf{1 . 0 0 7}$ & $\mathbf{9 9 9}$ \\
\hline
\end{tabular}

Izvor: Đuro Đaković (2018 b)

Grafikon 1. Kretanje broja zaposlenih od 2015. do 2018. godine

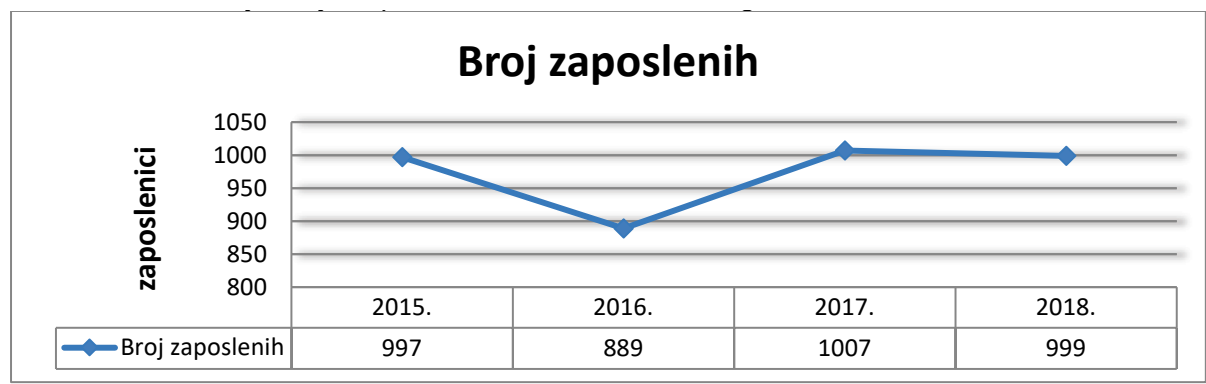

Izvor: Đuro Đaković (2018 a)

Nakon smanjenja, do kojeg je došlo u 2016. godini, broj zaposlenih vratio se na razinu iz 2015. i ostao gotovo nepromijenjen sljedeće dvije godine, što ukazuje na stabilizaciju poslovanja. Navedena stabilizacija može se uočiti i promatranjem prihoda i dobiti koji su prikazani grafikonima 2 i 3.

Grafikon 2. Poslovni prihodi grupacije po kvartalima od 2014. do 2018. godine, u milijunima kn

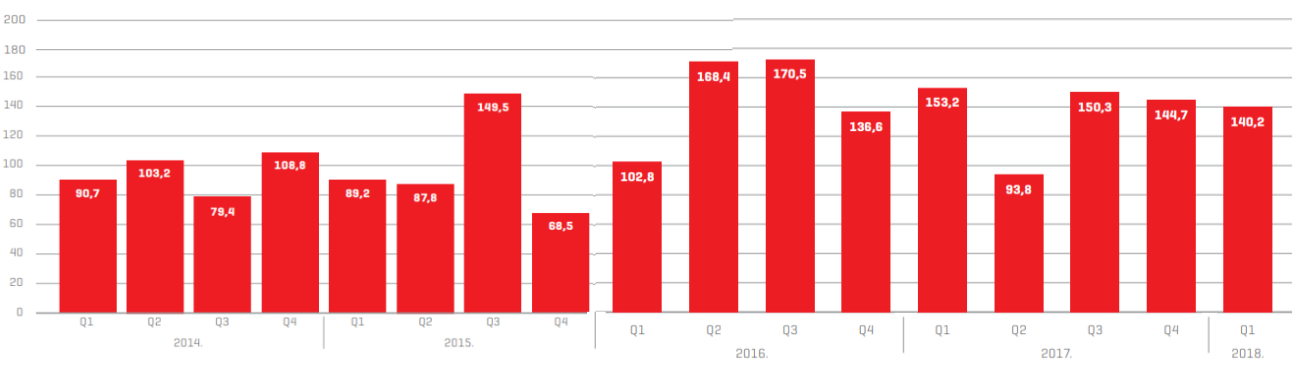

Izvor: Đuro Đaković (2017, 2018 a, 2018 b) 
Razdoblja su podijeljena u kvartale radi boljeg prikaza te radi jednostavnije usporedbe. Vidljivo je kako se poslovni prihodi povećavaju kroz promatrani vremenski period. Grupa je ostvarila 382,1 milijuna kuna ukupnih prihoda u 2014. godini. Godine 2015. grupa je ostvarila ukupan poslovni prihod u visini od 395 milijuna kuna. U 2016. godini grupa je ostvarila ukupno 578,3 milijuna poslovnih prihoda, što je povećanje u odnosu na 2015. godinu od 31,6 \% poslovnih prihoda. Sličan rezultat prodaje grupa je zadržala i 2017. godine, s ostvarenih 550 milijuna kuna prihoda.

Grafikon 3. EBITDA po kvartalima od 2014. do 2018. godine

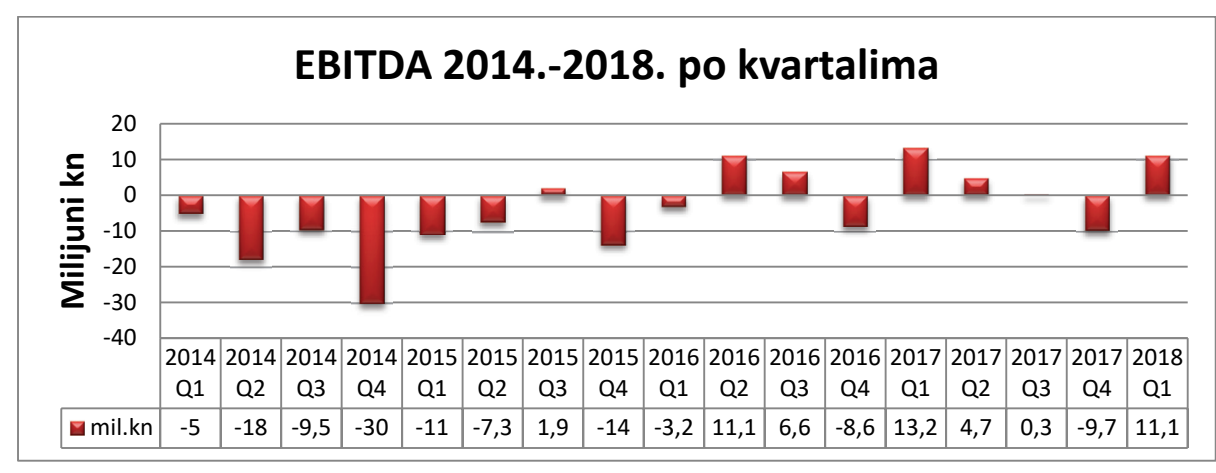

Izvor: Đuro Đaković (2017, 2018 a, 2018 b)

Konstantna dobit poduzeća na godišnjoj razini od 2016. godine nadalje, uz činjenicu da se broj zaposlenih ponovno podigao na razinu iz 2015. godine te uz vidljivo povećanje poslovnih prihoda, jasno ukazuje na stabilizaciju poslovanja grupacije

Dionica Đuro Đaković grupe kotira na hrvatskom tržištu vrijednosnih papira. Naziv dionice ne službenom tržištu je DDJH-R-A. Cijene dionice su sklone promjenama na dnevnoj razini, stoga su u nastavku priloženi podaci vjerodostojni za vremenski period u kojem je dionica promatrana. Podaci o dionici: izdavatelj: Đuro Đaković Holding d. d.; gospodarski sektor: Prerađivačka industrija; oznaka: DDJH; ukupna količina 12,78 mil; vrsta financijskog instrumenta: redovna dionica; nominalna vrijednost: $20,00 \mathrm{kn}$; trenutna cijena: $15,30 \mathrm{kn}$; najviša cijena u posljednjih 365 dana: 43,00 kn; najniža cijena u posljednjih 365 dana: 13,60 kn; apsolutno najviša cijena: 314,00 kn; apsolutno najniža cijena: 13,60 kn; dividenda: 0 kn (Zagrebačka burza, DDJH, 2018). Grafikonom 4 prikazano je kretanje dionice DDJH u posljednjih deset godina. 
Grafikon 4. Kretanje prosječne cijene DDJH-R-A od 2008. do 2018.

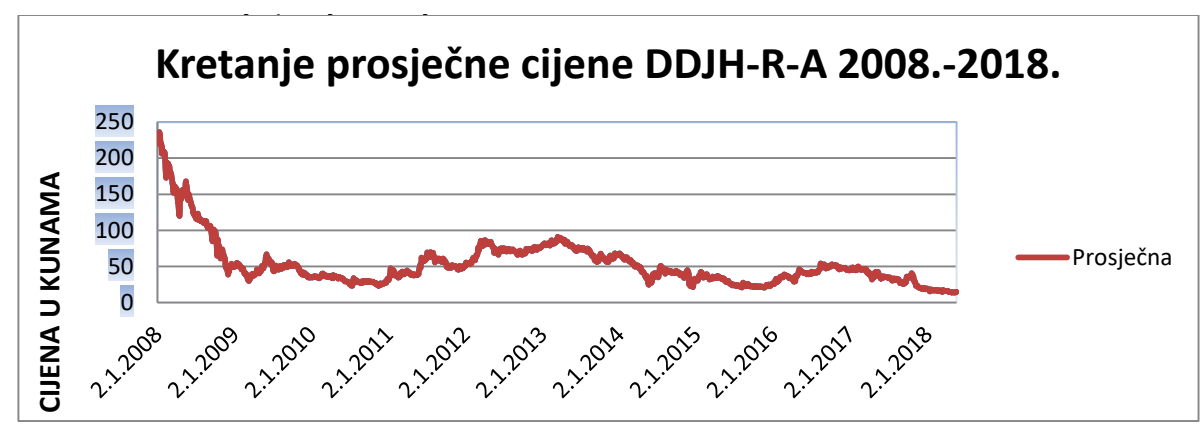

Izvor: http://www.zse.hr/

U vrijeme prije kraha burze cijena dionice kretala se oko psihološke granice od 250 kn, ali je potom došlo do povlačenja kapitala i preslagivanja na financijskim tržištima. Kao posljedica averzije investitora prema riziku te sklonosti ulaganja u manje rizične oblike imovine, značajan iznos sredstava na financijskim tržištima prelio se u novčane fondove ili bankovne depozite (Olgić Draženović et al., 2018). Globalna financijska kriza dovela je do vrlo slabe likvidnosti hrvatskog tržišta vrijednosnih papira, što je uz vrlo slabu tradiciju i kulturu ulaganja, prikupljanja kapitala i štednje u raznim oblicima vrijednosnih papira, te niske tolerancije prema riziku, dodatno usporilo njegov razvoj (Olgić Draženović et al., 2016). Zbog povezanosti razvoja financijskih tržišta i gospodarskog rasta smatra se da je ovakva situacija dugoročno nepovoljna (Buterin, Olgić Draženović, 2007 i Levine, 2002). Dionica DDJH tada je slijedila kretanja većine dionica na hrvatskoj burzi te je izgubila značajan dio svoje tržišne vrijednost. Sljedećih nekoliko mjeseci činilo se kao da je svaka nova cjenovna razina dno ispod kojeg se ne može ići. Stagnacija cijene na razini od ispod psiholoških 50 kuna potrajala je do početka 2012. godine, kada se činilo da započinje njezin oporavak i približavanje novoj granici od 100 kuna, no umjesto proboja granice od 100 kuna dolazi do obrata trenda i dionica pada do današnje razine od ispod 20 kuna.

\section{TEHNIČKA ANALIZA ĐURO ĐAKOVIĆ GRUPE D. D.}

Tehnička analiza predstavlja jednu od često korištenih tehnika analize na financijskim tržištima. $\mathrm{U}$ središtu promatranja je kretanje cijene dionice i volumena prodaje kroz određene vremenske periode (Mishkin, 2005). Na kretanja na financijskom tržištu značajno utječu i sentimenti sudionika povezani s vanjskim utjecajima (Shim et al., 2017), ali tehnička analiza isključuje i te utjecaje. Cilj tehničke analize je pravovremeno otkrivanje trenda ili smjera kretanja cijene dionice te predviđanje budućih događanja na financijskom tržištu sa svrhom potpore pri donošenju odluka o načinu i smjeru djelovanja na financijskim tržištima (Galetić et al., 2007). Zapravo, može se reći da je cilj tehničke analize shvaćanje tržišta prije obrata njegovih trendova (Kostolany, 1998).

\section{1 Analiza trenda}

Tehnička analiza temeljni je alat za kratkoročne i dugoročne analize trendova na financijskim tržištima i često ima daleko veću primjenjivost od fundamentalne analize (Lazibat, Matić, 2002). 
Svi izračuni u tehničkoj analizi imaju isključivo svrhu izmjeriti tržišni trend radi pravovremenog uključivanja u smjer trenda (Schwager et al., 1996). Trend predstavlja smjer kretanja cijene dionice, a može se podijeliti na padajući odnosno medvjeđi, rastući odnosno bikovski te horizontalni ili, češće nazivan, bez trenda (Maričić, 2011). Vremenski se trendovi klasificiraju u tri kategorije: glavni, duži od jedne godine, srednjoročni, s trajanjem do šest mjeseci te kratkoročni, od dva ili tri mjeseca (Buterin et al., 2015).U nastavku slijedi grafički prikaz promatranih trendova u različitim vremenskim razdobljima te njihovo kretanje i objašnjenja grafičkih prikaza.

Grafikon 5. Dugoročni i srednjoročni trend cijene DDJH-R-A 2017. - 2018.

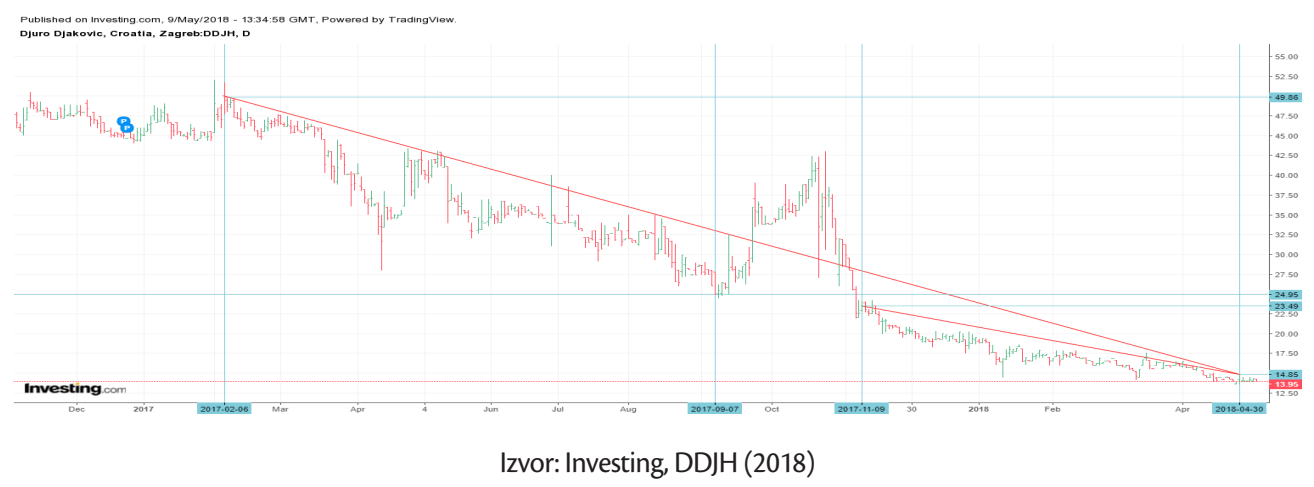

Prikazani su glavni i srednjoročni trend. Vidljivo je kako je trend silazan, odnosno, vidljivo je da se cijena dionica smanjuje kroz promatrani vremenski period, što ukazuje na medvjeđe tržište. Pad cijene započeo je 6. 2. 2017. godine te traje do 30. 4. 2018. godine. Glavni trend promatran je u razdoblju od 6.2.2017. godine do 30.4. 2018. odnosno ukupno 448 dana te se u tom vremenskom periodu cijena snizila sa $49,86 \mathrm{kn}$ po dionici na $14,85 \mathrm{kn}$ po dionici. To je smanjenje za $35,19 \mathrm{kn}$ po dionici odnosno za $70.32 \%$. Promatrajući glavni trend vidljivo je da se cijena u razdoblju od 22. 9 . 2017. podigla iznad linije trenda, što je bilo uzrokovano kratkotrajnom prekomjernom potražnjom, ali se cijena vratila na prijašnju razinu već 6.11 . 2017. godine te nastavila svoj padajući trend sve do 30.4. 2018.

Promatrajući srednjoročnu liniju trenda vidljivo je kako je trend od 9. 11.2017. također padajući, što se poklapa s glavnim trendom, te isto tako traje sve do 30.4 . 2018. godine. Razdoblje promatranja srednjoročnog trenda je 172 dana za vrijeme kojih se cijena od 23,45 kn po dionici snizila na 14,85 kn. Ostvaren je pad od $8,64 \mathrm{kn}$ po dionici odnosno $36,77 \%$. U promatranom razdoblju trend je padajući a tržište je medvjeđe.

\subsection{Volumen trgovine}

Volumen trgovine promatra se zbog svog velikog utjecaja na cijenu dionice te je važan podatak u provođenu analiza (Blume et al., 1994). Volumen trgovine podatak je koji značajno pridonosi pouzdanosti predviđanja i praćenja financijskih tržišta. Na grafikonu 6 vidljivo je kretanje cijene dionice i kretanje volumena trgovine dionice. 
Grafikon 6. Kretanje cijene dionice i volumen trgovine DDJH-R-A
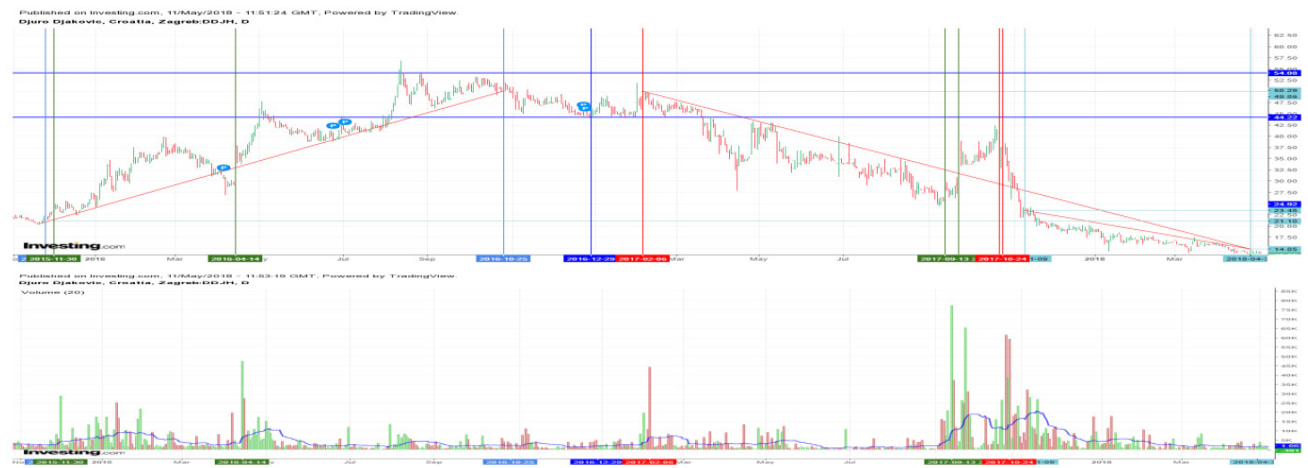

Izvor: Investing, DDJH (2018)

Kretanje cijene i volumen trgovanja dvije su međusobno zavisne varijable kod kojih promjena jedne dovodi do promjena druge varijable i obratno (Mishkin, 2010). Istaknuti su datumi u kojima se odvijao najviši volumen trgovine te prikazan prosjek kretanja volumena trgovine. Za vrijeme uzlaznog trenda istaknuti su datumi 30. 11. 2015. u kojem je volumen bio $29 \mathrm{~K}$ te 14. 4. 2016. s volumenom od $47 \mathrm{~K}$. Promatrajući silazni trend istaknuti su datumi 6. 2. 2017. s $45 \mathrm{~K}$, te 13. 9. sa 78 K i 22. 9. 2017. sa $66 \mathrm{~K}$ koji su doveli do povećanja cijene u rujnu, ali se cijena već nakon 20. 10. 2017. s trgovinom od $62 \mathrm{~K} \mathrm{i} \mathrm{25.} \mathrm{10.} \mathrm{2017.} \mathrm{sa} 60 \mathrm{~K}$ vratila na prethodnu razinu. Rezultat svega bio je pad prethodno povišene cijene i daljnii nastavak silaznog trenda.

\subsection{Pomični prosjeci}

Pomični prosjeci predstavljaju prosjek određenog skupa podataka (Prohaska et al., 1997). Pomični prosjek je alat koji se koristi kako bi se slijedili trendovi i predvidjele promjene njihova smjera. Njegova je svrha identificirati i signalizirati početak novog ili obrat postojećeg trenda (Edwards et al., 2007). Grafikonom 7 prikazani su pomični prosjeci s različitim vremenskim promatranjem i to metodom dvostrukog i trostrukog križanja u vrijednostima od 35,55 i 120 dana.

Grafikon 7. Pomični prosjeci DDJH-R-A 2017.-2018.

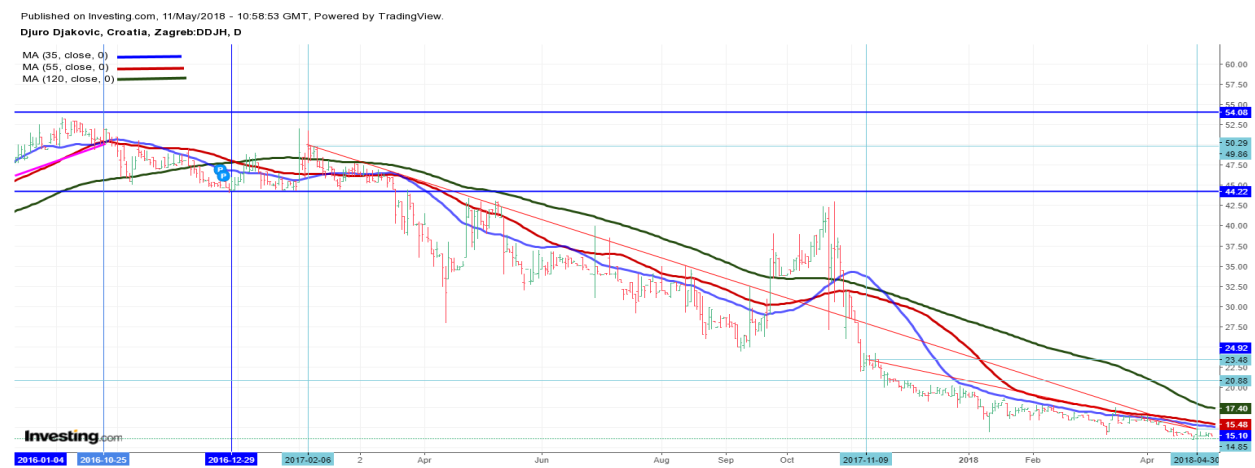

Izvor: Investing, DDJH (2018) 
Grafički su prikazani pomični prosjeci u razdoblju od 25. 10. 2016. do 30. 4. 2018. Dana 25. 10. 2016. pomični prosjeci od 35 i 55 dana su se presjekli, što je ukazalo na mogući obrat tržišta te najavu promjene trenda. Isto tako, 29. 12. 2016. su se presjekli prosjeci od 35 i 55 dana s prosjekom od 120 dana, što je također ukazivalo na promjenu trenda. Dana 6. 2. 2017. započinje opadajući trend koji traje sve do 30. 4. 2018. godine. $U$ tom vremenskom razdoblju 13.10. 2017. presjekli su se prosjeci od 35 i 55 dana, što je preliminarno ukazivalo na uzlaznu fazu cijene ali je ponovno presijecanje od 21. 11. 2017. nedvosmisleno ukazalo na vraćanje u prethodno stanje. Da je navedena promjena bila samo kratkotrajna oscilacija a ne i promjena značajnijeg karaktera, dokazuje i činjenica da nije došlo do presijecanja s trendom od 120 dana.

\section{4 Momentumi}

Momentum predstavlja osnovni oblik analize oscilatora. On mjeri brzinu cjenovnih promjena tako da se cijene za određeno fiksno razdoblje neprekidno oduzimaju. Momentumom se mjeri razlika između cijena u dva vremenska razdoblja (Murphy, 2007). Promatranjem kretanja linije momentuma može se primijetiti ubrzava li rastući trend ili su kapitalni dobitci jednaki onima iz prethodnog razdoblja te započinje li silazni trend. Korištenje dužeg momentuma smatra se učinkovitijim kod prepoznavanja obrata trenda. Grafikonom 8 prikazan su momentumi 14, 35 i momentum 50 .

Grafikon 8. Momentumi 14, 35, 50, DDJH-R-A 2017. - 2018.

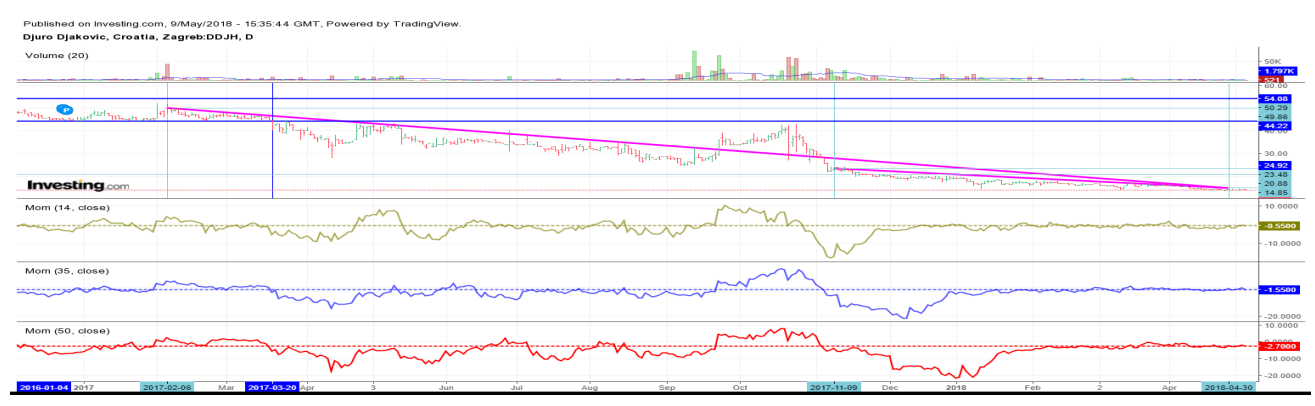

Izvor: Investing, DDJH (2018)

Grafički su prikazani momentumi od 14, 35 i 50 dana u razdoblju od 6. 2. 2017. do 30. 4. 2018. godine. Momentum od 14 je osjetljiv na nagle tržišne promjene u kraćem roku te se može uočiti kako se nalazi značajno iznad linije cijene 5. 5. 2017., dok su momentumi od 35 i 50 ispod te linije, što znači da ne sugeriraju mogući obrat trenda. Nekoliko mjeseci kasnije, točnije 22. 9. 2017., dolazi do ponovnog porasta momentuma iznad linije cijene. Momentumi od 14 i 35 osciliraju i više i brže. Rastući momentum od 50 pokazuje manji rast te se brzo vraća na razinu ispod linije cijene, pa potom nastavlja daljnje kretanje u negativnom smjeru. Kraći momentumi imali su veće oscilacije, što je razumljivo, ali uz pomoć dužeg momentuma se preciznije utvrđuje smjer i kretanje trenda te brzina promjena. Iz tog se razloga preporučuje koristiti duže momentume pri provođenju analiza ovakvog tipa. 


\subsection{Pokazatelj relativne snage}

Uz oscilator momentuma za jasnije rezultate koristi se i oscilator indeks relativne snage (Murphy, 2007). Pokazatelj relativne snage umanjuje distorzije koje nastaju kod momentuma zbog naglih promjena cijene te fiksira momentum u raspon od 0 do 100 (Agram brokeri, 2008). Prilikom interpretacije ovog oscilatora postoji pojam neuspješni zamah koji se događa kada je indeks ispod 30 ili 70 bodova. To se odnosi na slučajeve kada u rastućem trendu vrh indeksa relativne snage ne uspije premašiti prethodni vrh, pa time doseže i niže dno od prethodnog. Kod padajućeg trenda proces je obratan. Pokazatelj relativne snage promatrane dionice prikazan je na grafikonu 9.

Grafikon 9. Pokazatelj relativne snage DDJH-R-A 2017. - 2018.

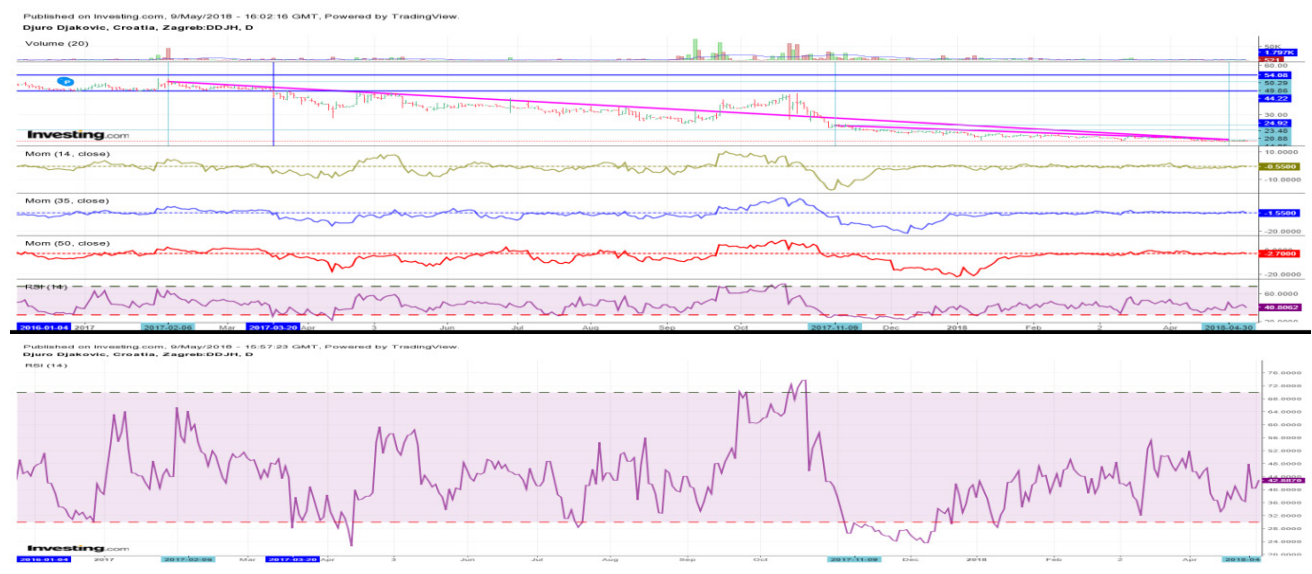

Izvor: Investing, DDJH (2018)

Pokazatelj relativne snage izračunat je na vrijednosti od 14 dana za razdoblje od 6. 2. 2017. do 30. 4. 2018. godine. Vidljivo je da je indeks 11. 1. i 1. 2. 2017. bio blizu gornje granice, ali je nije premašio. Zatim se indeks spustio na donju razinu koju je nakratko i uspio probiti 11. 4. 2017. Tadašnji porast cijene dionice rezultat je povećane potražnje, ali indeks se ubrzo stabilizirao te nije uspio premašiti gornju granicu. Zatim je uočljiv privremeni porast koji je trajao od 21. 9. do 19. 10. 2017. godine. $U$ to vrijeme indeks je zbog prekomjerne prodaje čak i prešao gornju razinu, međutim, kao posljedica prekomjerne prodaje ubrzo dolazi do korekcije i snižavanja indeksa ispod donje granice. Ta korekcija jasno je vidljiva 6.11. 2017. godine. Od 13. 12. 2017. nastupa razdoblje stagnacije kada se indeks podiže iznad donje granice te više ne pokazuje tendenciju naglih promjena nego se zadržava unutar raspona sve do 30.4. 2018. godine.

\subsection{MACD (Moving average convergence/divergece)}

Pokazatelj MACD služi za otkrivanje promjena u snazi, pravcu, momentumu i trajanju trenda. To je pokazatelj koji pokazuje odnos između dvaju pomičnih prosjeka cijena (Eric et al., 2009). MACD sadrži bržu i sporiju liniju. Brža MACD linija rezultat je dvaju eksponencijalno vaganih pomičnih prosjeka zaključnih cijena. Signalna linija ili sporija predstavlja eksponencijalno vagani pomični 
prosjek u posljednjih 9 razdoblja (Murphy, 2007). Grafikonom 10 prikazane su linije s 12, 26 i 9 razdoblja koje inače imaju i najveću primjenu u praksi.

Grafikon 10. MACD DDJH-R-A 2017. - 2018.

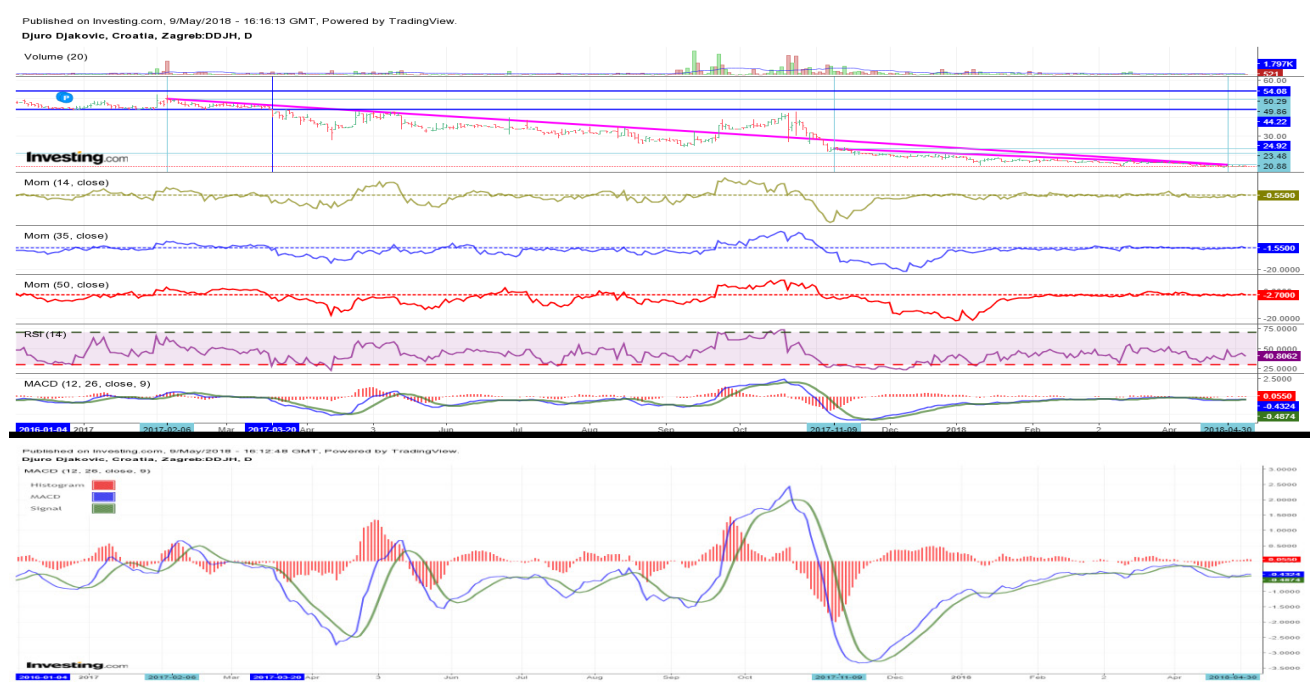

Izvor: Investing, DDJH (2018)

Grafički je prikazan oscilator MACD (Moving average convergence/divergece) u razdoblju od 6. 2. 2017. do 30. 4. 2018. Promatrajući signalnu i MACD liniju na grafičkom prikazu, vidljivo je kako se cijena mijenjala u razdoblju, ali trend je ostao nepromijenjen. Svaka promjena cijene dovodi do presijecanja signalne i MACD linije. Promatrajući grafički prikaz MACD oscilatora u trajanju silaznog trenda, odnosno medvjeđeg tržišta, primjećuju se dvije promjene cijene koje odskaču od ostalih i to dana 20. 4. 2017., kada nakratko započinje uzlazna faza, te dana 15. 5. 2017., kada se linije opet presijecaju te započinje pad cijena dionica. Nakon toga nije dolazio do većih promjena cijena do 12. 9. 2017., kada MACD linija opet presijeca signalnu liniju te započinje rast cijena dionica s $25,80 \mathrm{kn}$ do $40,87 \mathrm{kn}$. Rast traje do 20. 10. 2017., kada se MACD i signalna linija ponovno sijeku te kada silazni trend dobiva na snazi, što je vidljivo iz momentuma. Nakon pada momentum gubi na snazi, a MACD i signalna linija se ponovno presijecaju, ali bez promjena cijena, zbog negativnog trenda. U sljedećem periodu signalna i MACD linija kreću se bez velikih promjena te bez naznaka momentuma da će trend dobiti na snazi.

Provedena tehnička analiza pokazala je da je dionica kroz duži vremenski period imala silazni trend na financijskom tržištu. Promatran je silazni trend dionice u razdoblju od 448 dana te srednjoročni trend u razdoblju od 172 dana. Promatranjem oscilatora momentum uočava se kako negativan trend dobiva na snazi. Duži momentumi daju kvalitetnije smjernice za odlučivanje i djelovanje dok kratki momentum ima izrazitu osjetljivost na nagle promjene cijene, što može dovesti do pogrešnog tumačenja, te ga treba uzimati s izrazitim oprezom. Negativni trend kretanja dionice započeo je u veljači 2017. i traje do svibnja 2018. godine, sjednom izraženom cjenovnom oscilacijom koja je trajala od rujna 2017. godine do studenoga 2017. godine. Na svim pokazateljima može se 
uočiti nastala oscilacija. Pomični prosjeci od 35 i 50 dana presjekli su se. Nije došlo do presijecanja pomičnog prosjeka od 120 dana s ostalim linijama pomičnih prosjeka, što potvrđuje kratkoročnost te promjene. Momentumi od $14 \mathrm{i} 35$ dana pokazali su kako uzlazna putanja dobiva na snazi, dok se, promatrajući momentum od 50 dana, uočava kako se njegova linija jedva kreće iznad linije cijene, što ukazuje da je uzlazna snaga momentuma samo kratkotrajna. MACD oscilator u promatranom se periodu presjekao sa signalnom linijom, što je naznačilo porast cijene, ali je do kraja studenoga došlo do ponovnog presijecanja MACD-a i signalne linije, što je značilo nastavak silaznog trenda cijene dionice na medvjeđem tržištu. Analiza momentuma potvrđuje položenost linija uz liniju cijene, što znači da trend ne dobiva na snazi. Kretanje indeksa relativne snage je $u$ donjoj polovici promatranog raspona između signalnih linija te nema naznaka većih oscilacija. MACD signal kreće se ispresijecano u kratkim intervalima sa signalnom linijom, što pokazuje male promjene u cijeni, pa se može očekivati kako u kraćem vremenskom razdoblju neće doći do većih promjena cijene dionice.

\section{ZAKLJUČAK}

Đuro Đaković Holding d. d. osnovan je 1991. na temelju ugovora o osnivanju, a osnivači su: Hrvatski fond za razvoj, Hrvatsko željezničko poduzeće i tadašnje Složeno poduzeće Đuro Đaković. Danas grupaciju Đuro Đaković čine Đuro Đaković Holding d. d. kao matica i četiri društva, u kojima je Đuro Đaković većinski vlasnik.

Tehnička analiza pronalazi učestalu primjenu u praksi te je široko prihvaćen alat kojim se promatra, prati i pretpostavlja kretanje tržišta i tržišnih trendova u budućnosti, kao i snaga i utjecaj tih promjena, ne istražujući pritom uzroke i razloge tržišnih kretanja.

Analizirajući tržišni položaj dionice DDJH-R-A provedena je dugoročna, srednjoročna i kratkoročna tehnička analiza uz pomoć pokazatelja koji se u znanstvenoj i stručnoj literaturi smatraju vrlo pouzdanima. Smjer kretanja cijene dionice je silazan kroz cijelo promatrano razdoblje. Promatranjem pomičnih prosjeka vidljivo je presijecanje svih triju prosjeka u prosincu 2017. godine, što je potvrdilo obrat tržista te promjenu kretanja trenda. Potom cijena probija zonu potpore te dosadašnja zona potpore postaje zona otpora u sljedećem razdoblju. Vidljivo je veliko povećanje volumena trgovine na početku oscilacije sa značajnim porastom kupnje, te po završetku oscilacije s posljedičnim velikim porastom prodaje dionice. Indeks relativne snage u svojoj najvišoj točki probija gornju granicu pokazatelja te je u prekomjernoj prodaji, što je rezultiralo padom cijene.

Ipak, analizirajući sve pokazatelje uočava se kako linije pomičnih prosjeka postaju položenije, čime ukazuju na usporavanje silaznog trenda te moguću najavu obrata medvjeđeg tržišta. Linije se kreću u istom pravcu tako da ne izgleda kao da će doći do presijecanja u kraćem roku. Moglo bi uslijediti kraće razdoblje bez trenda nakon kojega, ako linije nastave mijenjati putanju, možda dođe do obrata smjera kretanja, njihovog presijecanja i najave početka bikovskog tržišta u dužem vremenskom periodu. Na promjenu cijena dionica utječu brojni vanjski i unutarnji čimbenici, a tehnička analiza u svojoj suštini ne proučava uzroke pojedinih promjena nego ih prihvaća kao činjenice. 


\section{V. Šarlija, M. Vuraić-Kudeljan, D. Buterin: Protokoli tehničke analize u razlučivanju podcijenjenosti od... Zbornik Veleučilišta u Rijeci, Vol. 7 (2019), No. 1, pp. 287-300}

lako rezultate ove, kao i svake druge tehničke analize treba tumačiti i primjenjivati s velikim oprezom, ipak se može zaključiti da se za promatranu dionicu predviđa slabljenje silaznog trenda u kratkom i srednjem vremenskom razdoblju, dok se u dužem vremenskom razdoblju može očekivati obrat tržišta, ali bez značajnijih skokova.

\section{LITERATURA}

Agram brokeri (2008) Uvod u tehničku analizu, Zagreb

Blume, L., Easley, D., O'Hara, M. (1994) „Market Statistics and Technical Analysis: The Role of Volume“.In: The Journal of Finance. 49 (1), p. 153-181. https://doi.org/10.1111/j.1540-6261.1994.tb04424.x

Buterin, V, Plenča, J., Buterin, D. (2015) „Analiza mogućnosti pariteta eura i dolara“. U: Praktični menadžment: Stručni časopis za teoriju i praksu menadžmenta, 6(1), p. 22-29

Buterin, V., Olgić Draženović, B. (2007) „Macroeconomic growth and financial sector in the Republic of Croatia“. In: 6th International Symposium Economy and Business 2007, Economic Development and Growth, 10-14 September. Sunny beach, Bourgas: Science Invest, p. 206-216

Đuro Đaković grupa d. d. (2018 a) Godišnje izvješće grupacije Đuro Đaković i društva Đuro Đaković grupa d. d. I - XII 2017, Slavonski Brod

Đuro Đaković grupa d. d. (2018 b) Kvartalno izvješće grupacije Đuro Đaković i društva Đuro Đaković grupa d. d. I - III 2018., Slavonski Brod

Đuro Đaković grupa d. d. (2017) Godišnje izvješće grupacije Đuro Đaković i društva Đuro Đaković grupa d. d. I - XII 2016, Slavonski Brod

Edwards D. R., Magee J., Bassetti W. H. C. (2007) Technical analysis of stock trends 9th edition, New York: Taylor \&Francis Group

Eric, D., Andjelic, G., Redzepagic, S. (2009) „Application of MACD and RVI indicators as functions of investment strategy optimization on the financial market". U: Zbornik radova Ekonomskog fakulteta u Rijeci, 27(1), p. 171-196

Galetić, F., Herceg, T., Morić Milovanović, B. (2007) „Mikroekonomska analiza tržišta hrvatskih dioničkih investicijskih fondova". U: Zbornik Ekonomskog fakulteta u Zagrebu, 5(1), p. 431-437

Investing, DDJH (2018) https://www.investing.com/equities/djuro-djakovic-chart (21. 11. 2018)

Kostolany, A. (1998) Izazovi burze, Zagreb: LMN

Lazibat, T., Matić, B. (2002) "Fundamentalna i tehnička analiza cijena na terminskim tržištima, Ekonomski pregled" U: Ekonomski pregled, 53(5-6), p. 507-524

Levine, R. (2002) „Bank-based or Market-based Financial Systems: Which is better?“. In: Journal of Financial Intermediation, 11(4), p. 398-428. https://doi.org/10.1006/jfin.2002.0341

Maričić, Z., (2011) „Forex - karakteristike, trgovanje, tehnička i fundamentalna analiza“. U: Zbornik radova Međimurskog veleučilišta u Čakovcu, 2(1), p. 55-68.

Mishkin, F. S. (2010) Ekonomija novca, bankarstva i financijskih tržišta, Zagreb: Mate

Mishkin, F. S. (2005) Financijska tržišta + institucije, Zagreb: Mate

Murphy, J. J. (2007) Tehnička analiza financijskih tržišta: sveobuhvatni vodič za trgovinske metode i njihovu primjenu, Zagreb: Masmedia

Olgić Draženović, B., Maradin, D., Buterin, V. (2016) „Tax Framework of Croatian Financial system“. In: 5th International Scientific Symposium “Economy of Eastern Croatia - Vision and Growth”, Osijek: Sveučilište Josipa Jurja Strossmayera u Osijeku, Ekonomski fakultet Osijek, p. 1060-1068 
Olgić Draženović, B., Buterin, V., Prohaska, Z. (2018) „Uspon i pad investicijskih fondova u Republici Hrvatskoj“. U: Zbornik radova: 6. međunarodni simpozij "Savremene finansije i računovodstvo u kontekstu reformskih procesa u Bosni i Hercegovini”. Tuzla, BiH: OFF-SET d.o.o., p. 152-163

Prohaska, Z. et al. (1997) Mjesto i značenje tehničke analize u investicijskoj industriji. Računovodstvo, financije i revizija u suvremenim gospodarskim uvjetima, Pula: Hrvatska zajednica računovođa i financijskih djelatnika

Schwager, D. J. et al. (1996) Shwager on Futures, TehnicalAnalysi, New York: JohnWiley\&Sons, Inc.

Shim, H., Kim, M. H., Ryu, D. (2017) „Effects of intraday weather changes on asset returns and volatilities“, Zbornik radova Ekonomskog fakulteta u Rijeci: časopis za ekonomsku teoriju i praksu, Vol 35, No 2. https://doi.org/10.18045/ zbefri.2017.2.301

Zagrebačka burza, (2018), DDJH, http://zse.hr/default.aspx?id=10006\&dionica=584 (21. 11. 2018.)

Živkov, D., Njegić, J., Momčilović, M. (2018) „Bidirectional spillover effect between Russian stock index and the selected commodities", Zbornik radova Ekonomskog fakulteta u Rijeci: časopis za ekonomsku teoriju i praksu, Vol 36, No 1. https://doi.org/10.18045/zbefri.2018.1.29 


\title{
PROTOCOLS OF TECHNICAL ANALYSIS IN DETERMINING THE UNDERVALUATION FROM A LOW PRICE
}

\author{
Vedran Šarlija \\ Professional Specialist of Entrepreneurship, Tibljaška cesta 2, Croatia; e-mail: vedranv995@gmail.com
}

\section{Marijana Vuraić-Kudeljan}

MSc, Deputy Director, Ministry of Finance, Tax Administration, Boškovićeva 5, 10000 Zagreb, Croatia; e-mail: marijana.vuraic-kudeljan@porezna-uprava.hr

\section{Denis Buterin}

MSc, Senior Lecturer, Polytechnic of Rijeka, Vukovarska 58, 51000 Rijeka, Croatia;

e-mail:dbuterin@veleri.hr

\begin{abstract}
Financial markets are an essential component of the economic environment, and their trends are often studied by various interest groups. Although it is not possible to predict with complete certainty the trends in financial markets, owing to the development of science and technology today there are analytical protocols and tools that can quantify these trends while respecting certain limits and a certain level of risk. The authors investigate stock price movements of the group Đuro Đaković d.d. applying reliable indicators of technical analysis, they draw conclusions on future trends and future price levels in the short, long and medium term, with the aim of applying results to decision-making in investment processes. In each of the observed periods, the authors notice the presence of a negative trend. Such results are surprising given a relatively favorable position of the company on the market and its relative economic strength. Nevertheless, the analysis of momentum, the relative strength index and the MACD signal show the signs of weakening the negative trend in the short and medium term, while recovering and increasing to more price levels can be expected in the longer term.
\end{abstract}

Key words: tehnical analysis, financial markets, stock, risks, indicators 